\title{
The Use of Social Media for Medical Education Within Urology: a Journey Still in Progress
}

\author{
Kiana Saade ${ }^{1} \cdot$ Thomas Shelton $^{2} \cdot$ Michael Ernst $^{3}$ (1) \\ Accepted: 18 September 2021 / Published online: 16 December 2021 \\ (c) The Author(s), under exclusive licence to Springer Science+Business Media, LLC, part of Springer Nature 2021
}

\begin{abstract}
Purpose of Review This paper aims to discuss the growth of social media in urology over time, focusing on medical education platforms and best practices.

Recent Findings Social medial has facilitated physician and patient knowledge acquisition, conference participation, and mentorship. Several social media best practice statements are available, including from the American Urologic Association (AUA) and The European Association of Urology (EAU), to help ensure responsible use.

Summary The role of social media in urologic medical education has been amplified by the COVID-19 pandemic. Its utilization by urologists has been expanding, making it very valuable for physician and patient education. Future research should focus on ways to maximize these medical education efforts, minimize risks, and increase guideline awareness among users.
\end{abstract}

Keywords Social media $\cdot$ Medical education $\cdot$ Urology $\cdot$ Twitter $\cdot$ Facebook

\section{Introduction}

In recent years, social media has been one of the fastest growing mediums for interpersonal communication. Social media is defined as forms of electronic communication (such as websites for social networking and microblogging) through which users create online communities to share information, ideas, personal messages, and other content $[1 \bullet]$. Academic definitions further expand on this to emphasize social media as a way of sharing content, performing work functions, and creating online relationships and self-identities [2]. This means that everything from casual work emails and e-lectures to highly professional physician websites could potentially fit into definitions of social media. According to the latest statistics, 4.2 billion

This article is part of the Topical Collection on Education

Michael Ernst

Michael.ernst@nationwidechildrens.org

1 Jacobs School of Medicine and Biomedical Sciences, Buffalo, NY, USA

2 Ohio State University College of Medicine, Columbus, $\mathrm{OH}$, USA

3 Department of Urology, Nationwide Children's Hospital, Columbus, OH, USA people worldwide use social media, and an average person spends about 145 min daily on social media [3]. This makes it one of the most promising new ways in medicine to reach patients, students, and peers.

Social media has been adopted by many medical specialties, including urology. The purpose social media serves in urology has been broad and ranges from facilitating mentorship to being an integral part of medical education for both students and patients. Social media also allows physicians to deliver medical knowledge in an efficient way. The importance of social media as an outreach and educational tool has been made even more evident during the necessary social distancing brought on by the COVID-19 pandemic. This paper will discuss the use of social media in urological medical education, best practices, and future directions.

\section{Use of Social Media in Medicine}

Social media has become an important part of medical education in many specialties. Examples include social media-based visual databases of common skin conditions in Dermatology [4], educational renal physiology game in Nephrology [5], and tweetorial "e-chalk talks" [6]. Podcasts such as BehindTheKnife, Divine Intervention, and Surgery $101 \mathrm{can}$ also serve as tools for sharing medical education 
content, and are frequently closely tied to other social media presence. These podcasts often exist as part of independent websites with highly active comment sections or have associated Twitter accounts. The integrated social media aspect of these podcasts means that the creators can share their content while giving listeners a platform to engage with each other directly and quickly ask questions, discuss the material, or add clarification for other listeners. The easy accessibility and interactive components of these podcasts allow residents to efficiently learn and review board-related topics during their time outside of work. This creates a practical and convenient way of learning that enables busy residents to make efficient use of their time [7]. Social media allows for the close interaction of learners, facilitating organic and convenient engagement not seen in other mediums [8]. Given its growing presence, it is likely that the use of social media by all parties in the medical system will continue to grow upon its earlier and current uses.

Social media in urology has grown to encompass multiple areas including continued urologic knowledge acquisition, patient education, conference participation, and even professional mentorship.

\section{Knowledge Acquisition}

\section{For Medical Professionals}

The role of social media in facilitating continuing urologic education has become especially important during the ongoing pandemic where social distancing has limited many learning opportunities. When clinical rotations were paused, social media became an important means to continue resident and student education [9]. The Urology Collaborative Online Video Didactics (COVID) from University of California San Francisco (UCSF) is one example. This program is a multi-institutional collaboration that consists of 1-h-long didactic sessions given over Zoom and recorded that are then available on both YouTube (videos) and podcast channels such as Spotify. Every lecture focuses on a topic in urology and is given by a specialized faculty member from organizations across the country [10]. This lecture series demonstrates how social media-based lectures can reduce interruptions to learning, even during a global pandemic. Similarly, Pediatric Urology Fellowship Lectures Online (PedsUroFLO), also sponsored by UCSF, was created to continue pediatric urology education during the pandemic [11]. Other lecture series such as the EMPIRE (Educational Multi-institutional Program for Instructing Residents) Urology lecture series not only encompassed clinical topics but also addressed the hidden curriculum such as burnout and wellness [12]. Like with podcasts, the easy accessibility of these lectures on interactive platforms like YouTube can help open bidirectional dialogue via comment sections. They can be advertised and shared via Twitter, and their technical content and publication sources inherently help bring together a community of urologists, who are the target audience. This can help replicate the experience of informally discussing a lecture or presentation with colleagues. It is this added potential for a social aspect paired with technical, profession specific content, that helps make these e-lectures examples of social media. On an individual level, physicians have similarly used their own websites to share educational e-lectures and create professional or patient focused communities [13]. These examples demonstrate how current use of social media across a wide area of mediums have allowed for both general urology education, and the discussion of more niche topics to continue, even when many traditional avenues for urological education are being limited by COVID-19.

Given the wide array of social media-based educational initiatives, it is important to ask how effective they are at delivering knowledge. A study done by the European Society of Residents in Urology analyzed all social media platforms used by urology residents for educational purposes [14•]. The purpose of this study was to assess the perceived role of social media in knowledge acquisition. The study done in 23 different European countries with 316 respondents showed that social media was the third most important educational source after academic journals and society websites. YouTube was the most preferred tool for surgical technique videos. The perceived influence of social media on urology knowledge was rated as moderate to high by $63 \%$ and low to none by $37 \%$ of respondents. In addition, $59 \%$ agreed that altmetrics in social media could be considered in an academic promotion [14•]. This study showed that social media use for educational benefit is common, but its effectiveness still needs further investigation.

\section{For Patients}

The use of social media for medical education is not reserved for medical professionals. Social media is used by the public to share and obtain urological information in an easyto-access and understandable format. With more education about their medical condition, it is hoped that patients will have increased compliance and improved outcomes $[15,16]$. Social media can help facilitate this dynamic collaboration between the physician and patient.

Numerous investigations in various medical disciplines have demonstrated the effectiveness of social media for patient education. For example, a 2018 randomized controlled trial looking at the impact of social media-based education on vaccine-hesitant parents found that this intervention improved parent attitudes toward immunizations [17]. Furthermore, a pilot study by Newton et al. found that 
90\% of diabetic patients who participated in an intervention using blogs and online chat rooms felt more willing to comply with treatment [18]. Within urology, an analysis of online erectile dysfunction discussion boards have found that only $28 \%$ of posters to anonymous forums eventually seek professional medical advice, and young men often begin their search for medical answers through online chat rooms [19•]. Together these studies show that social media intervention can make a difference in patient engagement with care. Nevertheless, more formal studies are needed to assess and quantify how physician run social media impact urology patient care and satisfaction.

\section{Conference Participation}

Conferences remain crucial to continuing education in urology, and social media has created a means for participating in discussions related to the conference in real-time. Urologists have utilized this convenient tool to participate in and share conference-related information with people who are not in attendance. Increasing awareness of conference presentations is usually accomplished by using hashtags on Twitter created for a specific conference. This mechanism creates a space where all discussions related to a conference can be stored, and it also allows data collection and analysis of these tweets. For example, in 2018, there were more than 18,000 unique tweets using the hashtag \#AUA18, which represents a more than 300\% increase from 2013 [20]. Online platforms have also opened the door to hosting entirely virtual conferences during the COVID-19 pandemic. A cross-sectional survey conducted in China showed that the proportion of urologists that participated in virtual conferences increased from 69.4 to $90 \%$ during the pandemic. Given the increased participation in online conferences, it seems likely that social media will take on greater roles in promoting conferences and increasing attendee engagement. Further studies are still however needed to evaluate the exact ways in which conference attendees make use of catalogued conference tweets, and other social media during, and after, the event.

\section{Mentorship}

Social media can also be used for mentorship within medical education. This was evident during the most recent urology residency application cycle. With the cancellation of inperson away rotations as a result of COVID-19, it was difficult for medical students and aspiring urologists to seek out mentorship and create connections with urology residents and faculty at other institutions. One of the mentorship programs started on twitter was \#UroStream101 [21]. This program paired over 100 medical students with 90 urology residents across the country. Twitter-based mentorship programs created a novel use of social media in the era of social distancing. In McLuckey et al.'s "Harnessing the Power of Medical Twitter for Mentorship," the authors emphasize the importance of Twitter in providing mentorship to "minority groups who may otherwise struggle in their own institutions to find the unique mentorship that would most benefit them when left to traditional methods" [22]. The large number of social media users, and its remote nature, enables students to more effectively find mentors who are able to address their unique needs and can better tailor advice to their situation. This is especially important for students who may have small home urology programs, or none at all, because it expands and diversifies the pool of mentors available. The UCSF Urology Residents also launched the "UReTER - UnderRepresented Trainees Entering Residency" program, which seeks to provide mentorship to underrepresented groups as they undergo the urology match process. The UReTER program aimed to help increase the number of Black, Latinx, and other minority applicants [23]. Programs like UReTER are even more valuable in urology because of the small size of the field, and the separate match process that could make finding support more difficult at some institutions. Together these programs demonstrate how social media can afford a multitude of mentorship pathways by expanding access to mentors and connecting students with a greater degree of diversity in the mentorship available.

\section{Pitfalls and Safety Concerns}

While acknowledging the merits of social media, these positive aspects must be balanced with a discussion of responsible use to address concerns such as those pertaining to patient confidentiality and misrepresentation [24-28, 29••].

\section{Patient Confidentiality}

Using patient-based case studies for online learning on social media can be problematic. Protected health information, in all of its different forms, cannot be shared publically in these forums. A breach in confidentiality can affect patients' trust in the medical field and lead to not seeking further medical help [24]. Physicians should know and consult their departmental and institutional guidelines with regard to sharing clinical information on social media.

\section{Spread of False Information}

With increased digital freedom can also come a lack of content moderation. The spread of false medical information online can be damaging to medical providers, students, and patients. A PEW Foundation survey in 2013 in the USA revealed that 6 out of 10 Americans confer with online resources to diagnose a medical condition. Of those who found a diagnosis online, $35 \%$ said they did not follow-up 
with a visit to a professional medical provider [30]. The extent of trust put into social media accounts and the degree of reliance on unmoderated information are concerning, especially when it comes to the medical field. Within urology, an analysis by Alysouf et al. found that misinformation was present in up to $70 \%$ of articles on prostate cancer, and that inaccurate information was shared significantly more often verifiable data [31•]. These findings underscore the importance of critical appraisal of online resources and the importance of medical education put forth by credible resources and organizations.

\section{Conflict of Interest}

Financial conflict of interest (COI) has also been identified as a potential concern within social media medical education, specifically related to prostate cancer [32]. COI affects every aspect of medicine, including clinical care, teaching, and research [33]. Physicians and nurses are among the professions most trusted by the general public in the USA, and the influence of financial relationships may be underestimated by the public [34].

\section{Possible Solutions for Safety Concerns}

Several organizations have made efforts to establish safe use guidelines for social media, including the American Urologic Association (AUA) and The European Association of Urology (EAU).

The American Urological Association (AUA) published "Social Media Best Practices" and "Social Media Terms of Use" pages that guide urologists on how to properly and effectively use social media within the urological community. Specifically, the guidelines provided by the AUA stress professionalism, which is defined as the alignment of social media activities with the AUA's Code of Ethics. The Code of Ethics touches on the importance of accuracy when communicating with the public, and the disclosure of any conflicts of interests, when they may be present. This ethical code also includes maintaining qualification through study of the scientific basis of evidence and proof for medical knowledge. In the digital social media realm, we can interpret this to include the good faith communication of medical truth and refraining from the spread of false information. Other good social media practices, according to the AUA, include protecting confidentiality by never posting information such as names, or faceless pictures that could lead to patient identification of any type. The AUA also recommends that physicians are careful to respect others' opinions and refrain from using any insults or discriminatory remarks when engaging with patients online. In addition, one must be courteous and exercise discretion when publishing someone else's work.
When using social media, physicians should also keep in mind that what is posted may exist online indefinitely, and may be reflective of the AUA and what it represents [35]. Ultimately, the AUA best practices establish a framework for a positive online experience for both clinicians and patients.

The European Association of Urology (EAU) also created a committee of social media users and stakeholders to come up with a list that outlines good social media practices. The EAU guidelines recommend establishing a professional identity in line with career goals, assuming that any content posted is permanent, maintaining clear limits with patients, refraining from self-promotion, and not accepting casual online relationships with patients. They warn about mixing professional and personal content on social media accounts and recommend separating the two by creating two distinct accounts [36].

The British Journal of Urology International (BJUI) guidelines suggest users identify themselves as physicians, state that views are not necessarily those of one's institution, alert colleagues if their posts are inappropriate, and strive for accuracy [37].

A compendium of social media use guidelines from these three organizations (AUA, EAU, BJUI) is entitled "Guideline of Guidelines: Social Media in Urology" [38•]. There is a significant degree of overlap in the recommendations between these three societies with common themes of professionalism, maintenance of confidentiality, and establishing boundaries. While guidelines are important, actively teaching trainees safe online practices is critical to actualizing this content $[39,40 \bullet]$.

\section{Conclusions}

Social media platforms have the potential to greatly expand avenues for education, networking, and patient engagement in urology. While social media use for education has risks, the opportunities it provides the medical field are incredibly valuable, and have already been demonstrated by current, and early adopters within the field of urology. Safety concerns should not be ignored, but professional guidelines can help navigate these areas and create standards to help cultivate the potential of the online environment.

\section{Compliance with Ethical Standards}

Conflict of Interest Dr. Ernst, Ms. Saade, and Mr. Shelton have nothing to disclose.

Human and Animal Rights and Informed Consent This article does not contain any studies with human or animal subjects performed by any of the authors. 


\section{References}

Papers of particular interest, published recently, have been highlighted as:

- Of importance

$\bullet$ Of major importance

1.- Matta R, Doiron C, Leveridge MJ. The dramatic increase in social media in urology. J Urol. 2014;192(2):494-8. https://doi.org/10. 1016/j.juro.2014.02.043. This is a good review of the emergence and growth of social media use within urology specifically.

2. Manning J. Definition and Classes of Social Media. 2014. p. 1158-62.

3. Djordjevic M. Global social media usage statistics: how much time do people spend on social media?: Letter.ly; 2021.

4. Karimkhani C, Boyers LN, Ellis LZ, Brice S, Chen DL, Dunnick CA et al. Impact of a dermatology wiki website on dermatology education. Dermatol Online J. 2015;21(1).

5. Colbert GB, Topf J, Jhaveri KD, Oates T, Rheault MN, Shah $\mathrm{S}$, et al. The social media revolution in nephrology education. Kidney Int Rep. 2018;3(3):519-29. https://doi.org/10.1016/j. ekir.2018.02.003.

6. Cheston CC, Flickinger TE, Chisolm MS. Social media use in medical education: a systematic review. Acad Med. 2013;88(6):893-901. https://doi.org/10.1097/ACM.0b013e31828ffc23.

7. Petrucci AM, Chand M, Wexner SD. Social media: changing the paradigm for surgical education. Clin Colon Rectal Surg. 2017;30(4):244-51. https://doi.org/10.1055/s-0037-1604252.

8. Merchant RM, South EC, Lurie N. Public health messaging in an era of social media. JAMA. 2021;325(3):223-4. https://doi. org/10.1001/jama.2020.24514.

9. Ding M, Wang Y, Braga LH, Matsumoto ED. Urology education in the time of COVID-19. Can Urol Assoc J. 2020;14(6):E2312. https://doi.org/10.5489/cuaj.6696.

10. Urology Collaborative Online Video Didactics. UCSF. 2021. https://urologycovid.ucsf.edu/lecture-presentations. 2021.

11. PedsUroFLO: Pediatric urology fellowship lectures online. UCSF. 2021. https://pedsuroflo.ucsf.edu. 2021.

12. EMPIRE: Educational Multi-Institutional Program for Instructing REsidents. NYSAUA. 2021. https://nyaua.com/empire/. 2021.

13. Loeb S. Dr. Stacy Loeb MD, MSc, PhD (Hon). https://stacyloeb. com. 2021.

14. Rivas JG, Socarras MR, Patruno G, Uvin P, Esperto F, Dinis $\mathrm{PJ}$ et al. Perceived role of social media in urologic knowledge acquisition among young urologists: a European survey. Eur Urol Focus. 2018;4(5):768-73. https://doi.org/10.1016/j.euf. 2016.11.010. This is one of the only studies to look at the comparitive significance of different social media platforms in knowledge acquisition among trainees.

15. Lu X, Zhang R. Impact of physician-patient communication in online health communities on patient compliance: crosssectional questionnaire study. J Med Internet Res. 2019;21(5): e12891. https://doi.org/10.2196/12891.

16. Sanguansak T, Morley KE, Morley MG, Thinkhamrop K, Thuanman $\mathrm{J}$, Agarwal I. Two-way social media messaging in postoperative cataract surgical patients: prospective interventional study. J Med Internet Res. 2017;19(12): e413. https://doi.org/10.2196/jmir.8330.

17. Daley MF, Narwaney KJ, Shoup JA, Wagner NM, Glanz JM. Addressing parents' vaccine concerns: a randomized trial of a social media intervention. Am J Prev Med. 2018;55(1):44-54. https://doi.org/10.1016/j.amepre.2018.04.010.

18. Newton KT, Ashley A. Pilot study of a web-based intervention for adolescents with type 1 diabetes. J Telemed Telecare. 2013;19(8):443-9. https://doi.org/10.1177/1357633x13512069.
19.• Jiang T, Osadchiy V, Mills JN, Eleswarapu SV. Is it all in my head? Self-reported psychogenic erectile dysfunction and depression are common among young men seeking advice on social media. Urology. 2020;142:133-40. https://doi.org/10. 1016/j.urology.2020.04.100. This article shows the importance of meeting our patients where they are. We can no longer rely on them presenting to our clinic when they have an issue. Often times their first stop will be online.

20. Loeb S, Carrick T, Frey C, Titus T. Increasing social media use in urology: 2017 American Urological Association Survey. Eur Urol Focus. 2020;6(3):605-8. https://doi.org/10.1016/j.euf.2019. 07.004.

21. Ernst M, Badkhshan S. \#UroStream101: social media as a medium for mentorship in urology. Urology. https://doi.org/10.1016/j.urology. 2021.08.001.

22. McLuckey MN, Gold JA, O'Glasser AY, Hingle S, Spencer A, Fick LB. Harnessing the power of medical Twitter for mentorship. J Grad Med Educ. 2020;12(5):535-8. https://doi.org/10. 4300/jgme-d-20-00549.1.

23. Urology U. UReTER Mentorship Program is Launched. 2020.

24. Mansfield SJ, Morrison SG, Stephens HO, Bonning MA, Wang $\mathrm{SH}$, Withers $\mathrm{AH}$, et al. Social media and the medical profession. Med J Aust. 2011;194(12):642-4. https://doi.org/10.5694/j.13265377.2011.tb03149.x.

25. Bennett KG, Berlin NL, MacEachern MP, Buchman SR, Preminger BA, Vercler CJ. The ethical and professional use of social media in surgery: a systematic review of the literature. Plast Reconstr Surg. 2018;142(3):388e-e398. https://doi.org/10. 1097/PRS.0000000000004692.

26. Hennessy CM, Smith CF, Greener S, Ferns G. Social media guidelines: a review for health professionals and faculty members. Clin Teach. 2019;16(5):442-7. https://doi.org/10.1111/tct.13033.

27. Santhosh L, Carroll CL, Seam N. Tips and traps for trainees traversing social media. ATS Scholar. 2021;2(2):185-92. https:// doi.org/10.34197/ats-scholar.2020-0155PS.

28. Koo K, Bowman MS, Ficko Z, Gormley EA. Older and wiser? Changes in unprofessional content on urologists' social media after transition from residency to practice. BJU Int. 2018;122(2):33743. https://doi.org/10.1111/bju.14363.

29.• Dubin JM, Greer AB, Patel P, Carrion DM, Paesano N, Kettache $\mathrm{RH}$ et al. Global survey of the roles and attitudes toward social media platforms amongst urology trainees. Urology. 2021;147:64-7. https://doi.org/10.1016/j.urology.2020.09.007. This is a recent survey that characterizes the current use of attitudes towards social media amongst urology trainees. It accurately portrays where we stand now, a place of widespread use and continued growth. This growth must be intentional and supported to be most successful.

30. Kanekar AS, Thombre A. Fake medical news: avoiding pitfalls and perils. Fam Med Community Health. 2019;7(4): e000142. https://doi.org/10.1136/fmch-2019-000142.

31.• Alsyouf M, Stokes P, Hur D, Amasyali A, Ruckle H, Hu B. 'Fake news' in urology: evaluating the accuracy of articles shared on social media in genitourinary malignancies. BJU Int. 2019. https://doi.org/10.1111/bju.14787. This is article presents striking data regarding the prevalence false information shared about prostate cancer.

32. Loeb S, Katz MS, Langford A, Byrne N, Ciprut S. Prostate cancer and social media. Nat Rev Urol. 2018;15(7):422-9. https:// doi.org/10.1038/s41585-018-0006-0.

33. Fontanarosa P, Bauchner H. Conflict of interest and medical journals. JAMA. 2017;317(17):1768-71. https://doi.org/10. 1001/jama.2017.4563.

34. Fineberg HV. Conflict of interest: why does it matter? JAMA. 2017;317(17):1717-8. https://doi.org/10.1001/jama.2017.1869. 
35. Association AU. Social media best practices. Press Center. http:// auanet.mediaroom.com/index.php?s=20294. 2021.

36. Rouprêt M, Morgan TM, Bostrom PJ, Cooperberg MR, Kutikov A, Linton KD, et al. European Association of Urology (@ Uroweb) recommendations on the appropriate use of social media. Eur Urol. 2014;66(4):628-32. https://doi.org/10.1016/j. eururo.2014.06.046.

37. Murphy DG, Loeb S, Basto MY, Challacombe B, Trinh Qd, Leveridge $\mathrm{M}$ et al. Engaging responsibly with social media: The British Journal of Urology International (BJUI) guidelines. 2014.

38. Taylor J, Loeb S. Guideline of guidelines: social media in urology. BJU Int. 2020;125(3):379-82. https://doi.org/10.1111/bju.
14931. This is a nice summary of the guidelines put forth by the AUA, EAU, and BJUI.

39. Katz MS. Social media and medical professionalism: the need for guidance. Eur Urol. 2014;66(4):633-4.

40.• Davis WM, Ho K, Last J. Advancing social media in medical education. Cmaj. 2015;187(8):549-50. https://doi.org/10.1503/ cmaj.141417. This article is a good description of some of the pitfall of social media use and possible solutions to ensure safe use.

Publisher's Note Springer Nature remains neutral with regard to jurisdictional claims in published maps and institutional affiliations. 